\title{
List of PHOTOGRAPHS
}

John le Carré . . . . . . . . . . . . . . . . . . . . . . . 37

Mikhail Heifets. . . . . . . . . . . . . . . . . . 51

JB \& Lev Loseff, in Stokholm, December 1987 . . . . . . . . . . 89

JB \& Igor Efimov. . . . . . . . . . . . . . . . . . . . . . . 109

Edward Bloomstein, 2007, London . . . . . . . . . . . . . . 145

Mikhail Ardov in his church in Moscow . . . . . . . . . . . . . . . . 155

Oleg Tselkov . . . . . . . . . . . . . . . . . . 167

Tomas Venclova. . . . . . . . . . . . . . . . . . . . . . . 181

Viktor Golyshev . . . . . . . . . . . . . . . . . . . . 191

Aleksandr Sumerkin, 1997 . . . . . . . . . . . . . . . . . . 207

Joseph Brodsky and Petr Vail in Lucca, Italy, September 1995 . . . . . 219

JB \& Bengt Jangfeldt, at the reading in Stokholm. . . . . . . . . . 233

Ludmila Shtern . . . . . . . . . . . . . . . . . . . . . 245

JB's Inscription for Ludmila Shtern, 1977 . . . . . . . . . . . . 247

Zofia Ratajczak-Kapuścińska, 1960 s. . . . . . . . . . . . . . . . 269

Susan Sontag, Annie Apeboin \& JB, Venice, December 1977 . . . . . 287

Annelisa Alleva, Rialto, Venice, January 1983. . . . . . . . . . . . 335

Tatiana Retivov . . . . . . . . . . . . . . . . . . . 355

Tatiana Shcherbina, 15 September 2004 . . . . . . . . . . . . 375

Dasha Basmanova, July 2007. . . . . . . . . . . . . . . . . . 399

Pasha Basmanova, 2008 . . . . . . . . . . . . . . . . 403

Anastasiya Kuznetsova, 2008 . . . . . . . . . . . . . . . . 407

JB \& Seamus Heaney, by John Miniham, 1991 . . . . . . . . . . . 421

JB and Mark Strand in Provincetown, Autumn 1973 . . . . . . . . . 433

Les Murray, Derek Walcott, JB \& Seamus Heaney, 1988. . . . . . . . . 443

Jonathan Aaron. . . . . . . . . . . . . . . . . . . . . . 457

JB, Jonathan Aaron and Mark Strand in Provincetown, Autumn 1973 . . 461

William Wadsworth. . . . . . . . . . . . . . . . . 465

Les Murray . . . . . . . . . . . . . . . . . . . . 483

Sam Brussell . . . . . . . . . . . . . . . . . . . . . . . 509

Alan Myers, Joseph Brodsky \& Diana Myers in Cotswolds,

England, 1975. . . . . . . . . . . . . . . 517

JB \& his translator Daniel Weissbort, reading at London

Poetry Society, June 1979 . . . . . . . . . . . . . . . . . 543

Peter France . . . . . . . . . . . . . . . . . . . . 555

Michael Scammell . . . . . . . . . . . . . . . . . . . . . 567

Roger Straus, $1996 \ldots$. . . . . . . . . . . . . . . 587 